\title{
A case-control study on the treatment of protrusion of lumbar intervertebral disc through PELD and MED
}

\author{
HONG-PU SONG, HONG-FENG SHENG and WEI-XING XU \\ Department of Orthopedics, Tongde Hospital of Zhejiang Province, Hangzhou, Zhejiang 310012, P.R. China
}

Received March 6, 2017; Accepted June 20, 2017

DOI: 10.3892/etm.2017.4929

\begin{abstract}
We compared the clinical effects between the percutaneous endoscopic lumbar discectomy (PELD) and microendoscopic discectomy (MED) treatments for protrusion of lumbar intervertebral disc. We conducted a retrospective analysis on 60 patients who were diagnosed with single-segment protrusion of lumbar intervertebral disc during the period from January 2009 to June 2016. Patients were divided into two groups, the PELD and MED groups, which contained 30 cases each. We evaluated the operation results according to oswestry dysfunction index (ODI), visual analogue scale (VAS) and the improved MacNab standard. The average follow-up visit period after the operation was 18 months and the operation time of the two groups was not statistically different. The cadaverine quantity of bleeding in the PELD group is less than that in the MED group. Moreover, the average length of incision and the length of stay were shortened for the PELD group compared to the MED group. The ODI and VAS after operation for the two groups improved significantly compared to that before operation $(\mathrm{P}<0.05)$. The qualified rates of the PELD and MED groups were 93.0 and $90.0 \%$, respectively, as of the improved MacNab method. The complication occurrence rates for the two groups during perioperative period were not different. Therefore, the short-term efficacy of the two minimally invasive operation methods (PELD and MED) on the treatment of protrusion of lumbar intervertebral disc is satisfactory. In cases where operation indications are chosen strictly, PELD can be regarded as a method of safety and efficiency due to the advantages of minimal incision, less bleeding, minimal trauma and faster postoperative recovery.
\end{abstract}

\section{Introduction}

Protrusion of lumbar intervertebral disc is one of the most common diseases seen in department of orthopaedics with a

Correspondence to: Dr Hong-Feng Sheng, Department of Orthopedics, Tongde Hospital of Zhejiang Province, 234 Gucui Road, Hangzhou, Zhejiang 310012, P.R. China

E-mail: shenghongfeng888@163.com

Key words: protrusion of lumbar intervertebral disc, percutaneous endoscopic lumbar discectomy, microendoscopic discectomy morbidity of $20-35 \%$ for people older than 50 years (1-3). Risk factors include age, sex, bearing load for longtime (manual labour), gestation and trauma. Symptoms range from lower limb ache of different degrees, limb activity disorder, nerve injury and nerve sweeny, and $\sim 40-60 \%$ of patients need operative treatment (4). As for the traditional surgery, it combines the lumbar discectomy and fusion together and the patient needs to stay in bed for a long time which can result in complications such as bedsores, pneumonia and deep venous thrombosis in the lower limbs. Microendoscopic discectomy (MED) has the advantage of broad operation view, easier operation, minimal damage to the tissue surrounding (5). However, the operation levels are higher. The operative route and the operative process are similar to traditional excision which has limited minimal invasion. Percutaneous endoscopic lumbar discectom (PELD) combines the endoscope technique and radiofrequency technique organically and has the advantage of minimal invasion, minimal bleeding, easier anesthesia and faster postoperative recovery. As a result, it has been applied more widely in clinical use. In this study, PELD and MED were administered for patients with protrusion of lumbar intervertebral disc to analyze the safety and efficiency (6).

\section{Patients and methods}

Sample selection. We summarized 60 cases of patients with protrusion for lumbar intervertebral disc at the Department of Spine Surgery at first diagnosis and operative treatment retrospectively and the inclusion criteria were: i) Diagnosis through computed tomography (CT), magnetic resonance imaging (MRI) or contrast examination for intervertebral disc; ii) patients with pain of different degrees in the waist and lower limb and the results being positive for femoral nerve stretch test or sciatic nerve streth test; and iii) patients with indications of operation and the operative treatment being expected to be effective. The exclusion standards were: i) Patients with primary spinal stenosis, instraspinal neoplasm, spine trauma, intervertebral disc compression fracture; ii) patients complicated with underlying diseasessuch as organ dysfunction of heart, liver, lungs, kidney, brain which cannot stand the risk of operation and anesthesia; and iii) patients without enough clinical information.

This study was approved by the Ethics Committee of the Tongde Hospital and the written and signed informed consent was obtained from the patients or their relatives. We divided the patients into two groups, PELD and MED, according to 
Table I. Comparison of the baseline information of the two groups.

\begin{tabular}{|c|c|c|c|c|}
\hline Groups & $\operatorname{PELD}(\mathrm{n}=30)$ & MED group $(n=30)$ & $t / \chi^{2}$ test & P-value \\
\hline Male/female & $16 / 14$ & $17 / 13$ & 0.067 & 0.795 \\
\hline Age (years) & $54.8 \pm 6.5$ & $53.6 \pm 6.4$ & 0.233 & 0.724 \\
\hline Course of disease (months) & $3.2 \pm 1.3$ & $3.3 \pm 1.4$ & 0.256 & 0.681 \\
\hline $\begin{array}{l}\text { Protrusion of lumbar intervertebral } \\
\text { disc of central type }\end{array}$ & $6(20.0)$ & $7(23.3)$ & 0.269 & 0.874 \\
\hline Side central type & $16(53.3)$ & $14(46.7)$ & & \\
\hline Extreme lateral type & $8(26.7)$ & $9(30.0)$ & & \\
\hline $\begin{array}{l}\text { Lesion segments L5-S1 } \\
\text { L4-5 } \\
\text { L2-4 } \\
\text { T12-L2 }\end{array}$ & $\begin{array}{r}12(40.0) \\
6(20.0) \\
5(16.7) \\
7(23.3)\end{array}$ & $\begin{array}{r}13(43.3) \\
5(16.7) \\
6(20.0) \\
6(20.0)\end{array}$ & 0.299 & 0.960 \\
\hline Radiating pain of lower limb & $18(60.0)$ & $16(53.3)$ & 0.271 & 0.602 \\
\hline Cauda equine injury & $4(13.3)$ & $6(20.0)$ & 0.480 & 0.488 \\
\hline Lower limb activity disorder & $10(33.3)$ & $9(30.0)$ & 0.077 & 0.781 \\
\hline
\end{tabular}

PELD, percutaneous endoscopic lumbar discectomy; MED, microendoscopic discectomy.

the treatment methods. The baseline information of the two groups were not different as shown in Table I.

Study methods. This study was completed by the same operating and nursing team according to the standard medical process. Continuous epidural anesthesia was given for the MED group and local anesthesia for the PELD group.

Patients in the MED group adopted a prone position, lying on the spinal operation racks with abdomen hanging in the air. We located the working routeway using X-ray machine (Philips Research Laboratories, Eindhoven, Netherlands) for perspective. The Kirschner wire (Nanjing Jiancheng Co., Nanjing, China) was inserted into the right intervertebral space. We incised $1.8 \mathrm{~cm}$ by taking the wire as center and fixed the working routeway through expanding the insert by bushing by degrees. We cleared the soft tissue and ligamentum flavum in sight and exposed the dural sac and nerve root. We stripped the adhesion and pulled the nerve root towards the outside through a nerve hook. We also exposed the protruding intervertebral disc, used bipolar coagulation for hemostasis and intervertebral disc scalpel for excision. We took the intervertebral disc tissue of lesion out through nucleus pulposus forceps holder and irrigated the working routeway with a sterile saline solution of $0.9 \%$ and sutured the skin (Fig. 1).

The operation process for the PELD group was as follows: i) Locate the puncture point, demarcate the horizontal line (which passes through the superior border of intervertebral disc and the midcourt line of lumbar vertebra spinous process) and side position line (which passes through superior border of intervertebral disc along the dip direction of intervertebral space); use the intersection of the two lines as the puncture point. ii) Discography, under the post-anterior perspective of the X-ray, use no. 18 puncture needle to puncture to the ideal position through puncture point; penetrate into the protruding intervertebral disc through no. 18 needle, put no. 22 aortography needle into the center of intervertebral disc and inject the contrast agent (with omnipaque to methylene blue of 3:1).iii) Working routeway, make an incision of $0.7 \mathrm{~cm}$ taking no. 22 needle as the centre and fix the working route way through inserting expanding bushing by grades. iv) Excision, put the PTED in through the working route; continue irrigation with $2,500 \mathrm{ml} \mathrm{NaCl}$ solution of $0.9 \%$ with gentamicin ( 0.16 million $U)$ and epinephrine ( $1 \mathrm{mg}$ ) inside to keep the view clear. Find the nucleus pulposus of aizen degeneration; make excision and bring it out and search and expose the nerve fully. Use bipolar RF for the coagulation and hemostasis of annulus fibrosus. iv) Irrigate the working routeway time again with a $0.9 \% \mathrm{NaCl}$ solution. The skin was sutured without drainage tube (Fig. 2).

Observational index and evaluation methods. We compared the operation time, cadaverine quantity of bleeding during operation, average length of incision and the time of rest after operation. We adopted VSA to evaluate the ache levels, 0 (without ache) to 10 (unbearable sharp ache), for evaluation. The dysfunction of patients was scored according to oswestry dysfunction index (ODI) with the range from 0 (without dysfunction) to 5 (with the most obvious dysfunction) and from three points (10 items) of ache (ache level, influence on sleep), single-ability (carry items, sitting, standing, walking) and personal comprehensive ability (daily activities ability, social activity, sexual life and outing excursion). We obtained the ODI with 100 being divided by the score; thus, dysfunction is more serious as the index is bigger. The average follow-up visit period after operation was 18 months. The operation results can be divided into four degrees of excellent, good, medium and poor according to the improved MacNab standard. The conditions of complication during perioperative period were recorded.

Statistical analysis. Statistical analysis software SPSS 19.0 (IBM, Armonk, NY, USA) was used for data processing and 

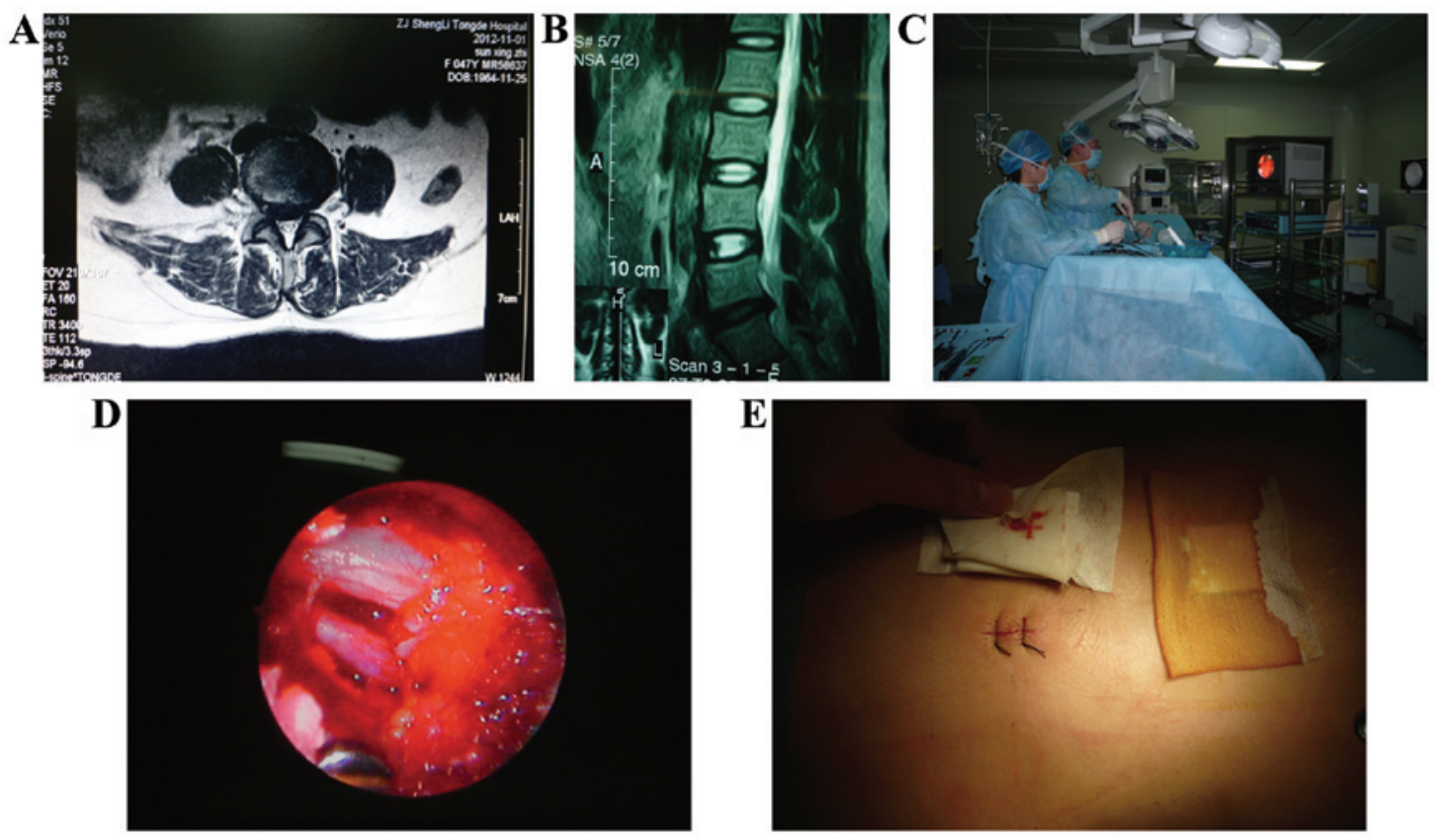

Figure 1. Images for a typical MED case. (A) MRI shows L5/S1 diskal hernia; (B) MRI shows L5/S1 diskal hernia; (C) nucleus pulposus is removed under diskoscope in surgery; (D) nerve root is deboned under diskoscope after nucleus pulposus is taken out; and (E) MED operative incisions. MED, microendoscopic discectomy; MRI, magnetic resonance imaging.
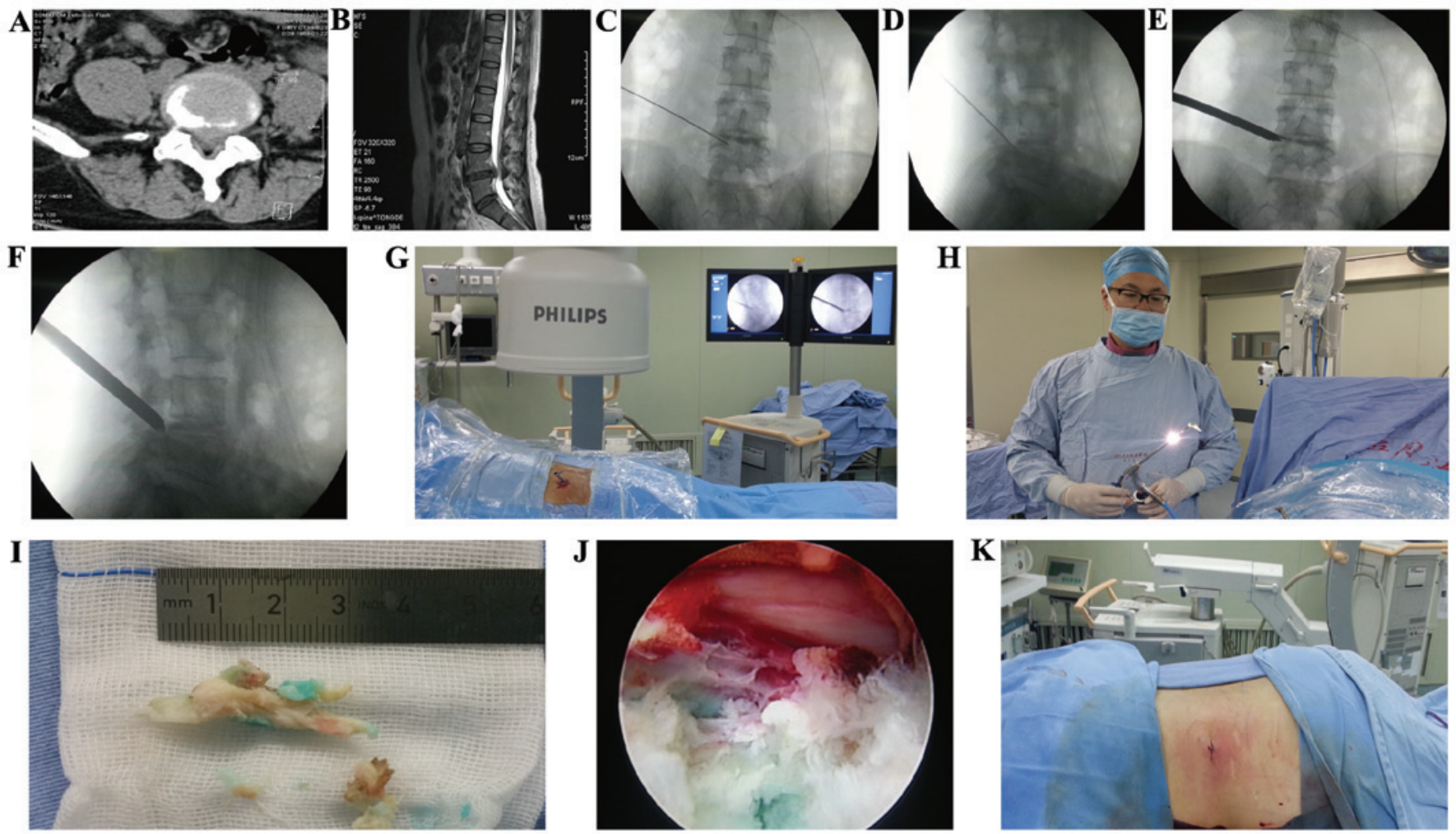

Figure 2. Images for a typical PELD case. (A) CT shows L4/5 diskal hernia before surgery; (B) MRI shows L4/5 diskal hernia before surgery; (C) puncture and radiography; (D) puncture and radiography; (E) positioning of the tube; (F) positioning of the tube; (G) the tube in the body; (H) a large nucleus pulposus is removed; (I) nucleus pulposus is removed; (J) nerve root deboned under PELD; and (K) PELD operative incisions. PELD, percutaneous endoscopic lumbar discectomy; CT, computed tomography; MRI, magnetic resonance imaging.

all the measurement data are shown as the mean \pm standard deviation (SD). We chose t-test for comparison among groups and compared the normal distribution data of different points in time within group and analyzed the variance of data through repeated measure. We adopted the $\chi^{2}$ test (for rectification) for enumeration data. The rank sum test was also used. $\mathrm{P}<0.05$ was considered to indicate a statistically significant difference. 
Table II. The comparison of the time of operation, cadaverine quantity of bleeding during operation, average length of incision and the time in bed after operation.

\begin{tabular}{lcccc}
\hline Groups & $\begin{array}{c}\text { The time of } \\
\text { operation (min) }\end{array}$ & $\begin{array}{c}\text { Cadaverine quantity } \\
\text { of bleeding during } \\
\text { operation (ml) }\end{array}$ & $\begin{array}{c}\text { Average length } \\
\text { of incision (cm) }\end{array}$ & $\begin{array}{c}\text { The time in bed } \\
\text { after operation (days) }\end{array}$ \\
\hline PELD & $78.7 \pm 13.4$ & $50.6 \pm 18.3$ & $0.8 \pm 0.2$ & $1.3 \pm 0.5$ \\
MED & $76.6 \pm 15.5$ & $100.7 \pm 46.5$ & $1.7 \pm 0.6$ & $5.6 \pm 0.7$ \\
t-test & 0.676 & 5.325 & 0.020 & 5.621 \\
P-value & 0.324 & 0.024 & 0.022 \\
\hline
\end{tabular}

PELD, percutaneous endoscopic lumbar discectomy; MED, microendoscopic discectomy.

Table III. Comparison of VAS scores.

\begin{tabular}{lccccc}
\hline Groups & $\begin{array}{c}\text { Before } \\
\text { operation }\end{array}$ & $\begin{array}{c}\text { One month } \\
\text { after operation }\end{array}$ & $\begin{array}{c}\text { Six months } \\
\text { after operation }\end{array}$ & $\begin{array}{c}\text { Twelve months } \\
\text { after operation }\end{array}$ & $\begin{array}{c}\text { F-value } \\
\text { P-value }\end{array}$ \\
\hline PELD & $4.5 \pm 1.1$ & $2.6 \pm 0.7$ & $1.3 \pm 0.4$ & $0.2 \pm 0.1$ & 8.627 \\
MED & $4.6 \pm 1.2$ & $2.5 \pm 0.8$ & $1.5 \pm 0.5$ & $0.2 \pm 0.1$ & 8.457 \\
t-test & 0.386 & 0.453 & 0.541 & 0.006 & $<0.001$ \\
P-value & 0.645 & 0.582 & 0.461 & 0.948 & \\
\hline
\end{tabular}

VAS, visual analogue scale; PELD, percutaneous endoscopic lumbar discectomy; MED, microendoscopic discectomy.

Table IV. Comparison of ODI scores.

\begin{tabular}{lccccc}
\hline Groups & $\begin{array}{c}\text { Before } \\
\text { operation }\end{array}$ & $\begin{array}{c}\text { One month } \\
\text { after operation }\end{array}$ & $\begin{array}{c}\text { Six months } \\
\text { after operation }\end{array}$ & $\begin{array}{c}\text { Twelve months } \\
\text { after operation }\end{array}$ & $\begin{array}{c}\text { F-value } \\
\text { P-value }\end{array}$ \\
\hline PELD & $30.8 \pm 7.4$ & $11.6 \pm 3.8$ & $5.5 \pm 1.4$ & $1.3 \pm 0.4$ & 16.235 \\
MED & $31.6 \pm 7.5$ & $13.7 \pm 4.3$ & $5.7 \pm 1.6$ & $1.2 \pm 0.3$ & 14.857 \\
t-test & 0.218 & 0.767 & 0.412 & 0.257 & $<0.001$ \\
P-value & 0.825 & 0.325 & 0.635 & 0.764 & \\
\hline
\end{tabular}

ODI, oswestry dysfunction index; PELD, percutaneous endoscopic lumbar discectomy; MED, microendoscopic discectomy.

Table V. Comparison between treatments effects (example, \%).

\begin{tabular}{lcccccc}
\hline Groups & Cases & Excellent & Good & Qualified & Poor & Rate (excellent and good) \\
\hline PELD & 30 & $13(43.3)$ & $15(50.0)$ & $1(3.3)$ & $1(3.3)$ & $28(93.3)$ \\
MED & 30 & $14(46.7)$ & $13(43.3)$ & $2(6.7)$ & $1(3.3)$ & $27(90.0)$ \\
Z/ $\chi^{2}$ test & & & 0.381 & & $<0.001$ & 1.000 \\
P-value & & & 0.826 & & \\
\hline
\end{tabular}

PELD, percutaneous endoscopic lumbar discectomy; MED, microendoscopic discectomy.

\section{Results}

Comparison of the time of operation, cadaverine quantity of bleeding during operation, average length of incision and rest after operation. The operation time of the two groups is not statistically significant. Furthermore, the average length of incision and the length of stay were shortened for the PELD group compared to the MED group. The 
difference was statistically significant $(\mathrm{P}<0.05)$ as shown in Table II.

Comparison of visual analogue scale (VAS) scores. As shown in Table III, the VAS scores of the two groups reduced as the time was extended and there is no statistical significance of difference between the two groups $(\mathrm{P}>0.05)$.

Comparison of ODI scores. As shown in Table IV, the ODI scores of both groups are decreased as the time was extended; there is no statistical significance of difference between the two groups $(\mathrm{P}>0.05)$.

Comparison between treatment effects and complications. It is not necessary to compare the difference between treatment effects and complications of two groups statistically $(\mathrm{P}>0.05)$. Both groups have severe wound infection, intervertebral disc relapsing dislocation, nerve or blood vessel damage and vertebral instability (Table V).

\section{Discussion}

Prolapse of lumbar intervertebral disc occurs when the intervertebral disc has retrogression and is under external force. In this case, the intervertebral disc tissue fiber is damaged and has water loss, cauda equine and nerve root suffers mechanical compression coming from nucleus pulposus which causes extreme lumbago and radiating pain in lower limbs. Under serious circumstances, it may lead to gatism, neurological deficit, foot drop or even paralysis (7).

Microscopic endoscopic treatment is carried out in place of display system, surgical channel and surgical instruments. With the combination of micro-endoscopic technique and traditional open surgery, the surgical field of micro-endoscopy will be effectively amplified, and coupled with good lighting system providing the doctor with a clearer field of vision. Therefore, it minimizes damage to surrounding tissues by fine operation (8). However, due to the two-dimensional image and under non-direct vision circumstances, it leads to larger difficulties in operation and high-level requirements on the surgeon. Local hospitals with limited medical resources may face many difficulties for this operation (9). In addition, nerve root may be pulled in surgery in order to expose protuberances which easily produces nerve root damage and adhesion. It is the same with traditional surgery, and is minimally invasive (10).

PELD can puncture and undergo accurate positioning, after disc herniation foramen ipsilateral punctures directly to the salient points from outside to inside, braking through the posterior-lateral, far lateral and interlaminar approaching limitations; in this way, you can reach any section segment (11). Cannula inserted through to expand the foramen intervertebral for grinding zygopophysis. It is clearly viewed under the endoscope, and surgery can be done in a direct vision manner. There is no structural damage on the ligament and the neural plate does not need to be removed; thus, it is conducive to the stability of the lumbar spine (12), and use of bipolar radiofrequency coagulation of the annulus collagen fibers destruction and nerve endings to reduce pain (13).

The present study shows that there were no significant differences in the operation time between these two groups.
The PELD group has less blood loss than the MED group; it has shorter average length of incision and shorter hospital stay time than the MED group. In PELD and MED groups, the ODI and VAS are significantly improved compared to those before surgery. The rate (excellent and good) of PELD and MED groups is 93.0 and $90.0 \%$, respectively. There are no differences in perioperative complication rates between the two groups. In conclusion, PELD and MED are two types of minimally invasive surgical treatments of lumbar disc herniation, whose short-term efficacy is satisfactory. With the choice of surgical indications under strict circumstances, PELD makes a small incision, which leads to less bleeding, fewer traumas and faster postoperative recovery and other advantages, and is a safe and effective surgical method.

\section{References}

1. Pandit P, Talbott JF, Pedoia V, Dillon W and Majumdar ST: T1@ and T2-based characterization of regional variations in intervertebral discs to detect early degenerative changes. J Orthop Res 34: 1373-1381, 2016.

2. Shin JS, Lee J, Kim MR, Jung J, Shin BC, Lee MS and Ha IH: The short-term effect of integrated complementary and alternative medicine treatment in inpatients diagnosed with lumbar intervertebral disc herniation: A prospective observational study. J Altern Complement Med 22: 533-543, 2016.

3. Riesenburger RI and David CA: Lumbar microdiscectomy and microendoscopic discectomy. Minim Invasive Ther Allied Technol 15: 267-270, 2006.

4. Huang CJ, Tang HW, Liang DB, Lou YM and Guan W: Treatment of the recurrent lumbar disc herniation: A comparison between endoscopic surgery and open surgery. Zhongguo Gu Shang 26: 810-814, 2013 (In Chinese).

5. Gadjradj PS and Harhangi BS: Percutaneous transforaminal endoscopic discectomy for lumbar disk herniation. Clin Spine Surg 29: 368-371, 2016.

6. Gadjradj PS, van Tulder MW, Dirven CM, Peul WC and Harhangi BS: Clinical outcomes after percutaneous transforaminal endoscopic discectomy for lumbar disc herniation: A prospective case series. Neurosurg Focus 40: E3, 2016.

7. Orita S, Inage K, Sainoh T, Fujimoto K, Sato J, Shiga Y, Kanamoto H, Abe K, Yamauchi K, Aoki Y, et al: Lower lumbar segmental arteries can intersect over the intervertebral disc in the oblique lateral interbody fusion approach with a risk for arterial injury: Radiological analysis of lumbar segmental arteries by using magnetic resonance imaging. Spine (Phila Pa 1976) 42: 135-142, 2017.

8. Zhao LJ, Jiang WY, Ma WH, Xu RM and Sun SH: Micro-endoscopic discectomy for the treatment of lumbar disc herniation in senile patients over seventy years old. Zhongguo Gu Shang 24: 811-815, 2011 (In Chinese).

9. Ye CP and Zhu JJ: Treatment of senile lumbar nerve root canal stenosis with micro-endoscope discectomy. Zhongguo Gu Shang 26: 805-809, 2013 (In Chinese).

10. Sinkemani A, Hong X, Gao ZX, Zhuang SY, Jiang ZL, Zhang SD, Bao JP, Zhu L, Zhang P, Xie XH, et al: Outcomes of microendoscopic discectomy and percutaneous transforaminal endoscopic discectomy for the treatment of lumbar disc herniation: A comparative retrospective study. Asian Spine J 9: 833-840, 2015.

11. Fan G, Guan X, Sun Q, Hu A, Zhu Y, Gu G, Zhang H and He S: Puncture reduction in percutaneous transforaminal endoscopic discectomy with HE's lumbar LOcation (HELLO) system: A cadaver study. PLoS One 10: e0144939, 2015.

12. Fan G, Guan X, Zhang H, Wu X, Gu X, Gu G, Fan Y and He S: Significant improvement of puncture accuracy and fluoroscopy reduction in percutaneous transforaminal endoscopic discectomy with novel lumbar location system: Preliminary report of prospective Hello study. Medicine (Baltimore) 94: e2189, 2015.

13. Hu DX, Zheng Q, Zhu B, Ying XZ and Wang YF: Percutaneous intervertebral foramina endoscopic lumbar discectomy decompression for elder patients with lumbar spinal stenosis syndrome. Zhongguo Gu Shang 27: 194-198, 2014 (In Chinese). 